\title{
Jovens cuiabanos, interesses científicos e percepções sobre a teoria evolutiva
}

Young students from Cuiabá, scientific interests and perceptions about the evolutionary theory

Graciela da Silva Oliveira ${ }^{1}$

Rita Baldini da Costa ${ }^{2}$

Thayanny Rosalino de Magalhaes ${ }^{3}$

\section{Resumo}

Este trabalho tem como objetivo verificar percepções de alguns estudantes cuiabanos acerca de temas científicos, escolhas profissionais e opiniões sobre temas evolutivos. Participaram desta pesquisa 406 estudantes (55,6\% meninos) matriculados no $1^{\circ}$ ano do Ensino Médio de escolas públicas de Cuiabá - MT. As coletas de dados aconteceram através da aplicação de questionários, e as análises estatísticas foram realizadas com auxílio do pacote estatístico Software Statistical Package for Social Science (SPSS) 18.0. Os resultados encontrados apontam que há, entre os estudantes cuiabanos, o interesse em aprender Ciências na escola, destacando a motivação por entender sobre biologia humana. Entretanto, a proximidade com a Ciência ganha uma nova reconfiguração quando se trata da teoria evolutiva, já que a maioria dos estudantes não reconhece a validade da explicação científica para a origem humana e desconhece alguns conceitos evolutivos.

Palavras chave: Ciência escolar; Evolução biológica; Ensino Médio; Percepção pública.

\section{Abstract}

The aim of this study was to learn about the perceptions of some students about scientific themes, their professional choices as well as their opinions about evolutionary themes. Four hundred and six (406) students participated of this research, 55.6\% were young male students enrolled in the $1^{\text {st }}$ year of High School in public schools in Cuiabá - MT. The data was generated from questionnaires and the statistical analyses were performed with the aid of the Statistical Package for Social Science (SPSS) 18.0. The results demonstrate that there is an interest in learning science in school among the students from Cuiabá. It can be highlighted their motivation to learn about human biology. Nevertheless, the proximity with science gains a new reconfiguration when the theme is the evolutionary theory, as most students do not recognize the validity of scientific explanations about human origin and are unaware of some evolutionary concepts.

Keywords: School Science; Biological evolution; High School; Public Perception.

\footnotetext{
${ }^{1}$ Universidade Federal do Mato Grosso - UFMT|graciela.ufmt@gmail.com

2 Universidade Federal do Mato Grosso - UFMT| rita.baldini@hotmail.com

3 Universidade Federal do Mato Grosso - UFMT| thayannyrosamagalhaes@gmail.com
} 


\section{Introdução}

Neste trabalho, apresentam-se resultados preliminares encontrados através do projeto de pesquisa "Percepções de jovens cuiabanos sobre evolução biológica: estudo das relações entre ciência e cultura", que tem como interesse aprofundar estudos acerca da percepção e valores atribuídos por jovens à ciência, tendo como referências as atitudes diante de tópicos sobre a teoria da evolução biológica e suas relações com a cultura.

De acordo com Vogt e Castelfranchi (2009), a maneira como os indivíduos percebem e utilizam o conhecimento científico articula-se em função da compreensão do conteúdo de ciências associada a contextos mais amplos de informações, como: atitudes, opiniões e valores que são atribuídos à ciência. Desta forma, construções cognitivas e afetivas interferem no modo como os jovens se relacionam com a ciência e os temas científicos.

Fatores inerentes às características dos estudantes e fatores ambientais influenciam nas atitudes, nos valores e nas opiniões sobre ciência e, consequentemente, esses sentimentos estão relacionados à forma como os jovens se relacionam com os diferentes temas científicos apresentados na escola. E para conhecer o que os jovens pensam, sentem e fazem quando se trata de ciência e, principalmente, quais fatores interferem nessas relações e construções de valores, é preciso dar voz a eles. Ouvir o que têm a dizer possibilita entender a relação da sociedade com a ciência, no presente e no futuro, pois esse segmento reflete os grupos, as imagens e as ideias disseminadas na população atual, assim como as atitudes e as opiniões apreendidas hoje devem influenciar as ações dos adultos de amanhã (OLIVEIRA, 2015).

Neste sentido, o entendimento moderno da teoria da evolução biológica - isto é, as percepções e os valores atribuídos pelos jovens à teoria evolutiva - também pode contribuir na compreensão de como os estudantes se relacionam com temas científicos e com a ciência ao longo da escolarização. A evolução biológica trata-se de um tema que apresenta um papel unificador das Ciências Biológicas, entretanto, as relações dos estudantes em diferentes fases de escolarização com temas evolutivos confirmam a falta de compreensão dos processos evolutivos e a resistência a diferentes estratégias de ensino (BIZZO, 1994). Entre as explicações para a defasagem de aprendizagem, destacam-se os fatores relacionados à maturidade psicológica e à presença de anacronismo nas reconstruções históricas (BIZZO; ALMEIDA; FALCAO, 2007; BIZZO; EL-HANI, 2009).

No Brasil, sobre os valores atribuídos à teoria da evolução biológica e religião, encontram-se dados nacionais no trabalho de doutoramento de Oliveira (2015) cujo objetivo foi ampliar e aprofundar discussões sobre as opiniões dos jovens brasileiros acerca da teoria da evolução biológica, bem como caracterizar possíveis relações entre o conhecimento e a aceitação de explicações científicas da evolução humana, com aspectos socioculturais e com a ciência. Além da pesquisa desenvolvida no Brasil, o mesmo conjunto de itens foi estudado no contexto italiano. Mais do que um estudo comparativo, da construção de valores atribuídos à ciência por jovens, oriundos de contextos socioculturais distintos, vislumbrou-se como esses diferentes contextos influenciam a construção de indicadores da percepção pública acerca de temas científicos.

Oliveira e Bizzo (2015) verificaram que há uma diversidade de opiniões e conhecimentos sobre a evolução e origem dos seres vivos. Quando verificado o conhecimento dos jovens a partir da autodeclaração, foi possível categorizar três situações: 1) conceitos reconhecidos como verdadeiros - nos quais a maioria dos jovens demonstrou-se convicta sobre a veracidade do conteúdo dos itens que se referem aos registros fósseis, à mudança das espécies e atribuição do conceito de evolução a plantas e animais; 2) conceitos que parecem 
confusos - houve maior oscilação nas três alternativas, e percebe-se o aumento dos jovens que não souberam responder sobre os itens que afirmavam acerca da idade da Terra, descendência do homem e a coexistência do homem e dinossauros; 3) conceitos desconhecidos - itens indicados com maior frequência para a alternativa "Não saberia dizer", que se referem à idade do homem na Terra e à ancestralidade comum.

Esses resultados parecem semelhantes aos dados encontrados por Mota (2013), que aponta que os jovens parecem dispostos a concordar com afirmações sobre os registros fósseis, mas apresentam incerteza diante de itens que versam sobre a ancestralidade em comum, e rejeitam com maior frequência a evolução humana. No entanto, a autora considera que, de maneira geral, os jovens apresentam posições positivas em relação à teoria evolutiva, do mesmo modo que parecem motivados com a religião, o que parece indicar que os estudantes convivem pacificamente com ambos os empreendimentos.

Apesar das atitudes positivas dos jovens diante de temas evolutivos e diante da ciência e seus desdobramentos, percebe-se que o conhecimento autodeclarado pelos estudantes é baixo, tanto a mudança dos organismos como a atribuição do conceito da evolução biológica à natureza são assuntos reconhecidos como válidos, porém, conceitos biológicos mais complexos são desconhecidos por eles, por exemplo, não há a percepção do mundo vivo enquanto uma unidade; além disso, não reconhecem o parentesco entre as espécies e a história do homem na Terra.

Quanto à origem do homem, há maior influência das ideias fundadas em crenças pessoais. Os jovens desconhecem a gênese humana, como evidenciam os percentuais atingidos na alternativa "Não saberia dizer", para a questão que abordava o tema. Quando os jovens optaram por uma explicação para a própria origem, a ideia da criação divina com as formas atuais foi a mais frequente (OLIVEIRA, 2015; OLIVEIRA; BIZZO, 2015).

No Brasil, evidenciou-se a falta de clareza entre os estudantes sobre a idade da Terra, as relações entre os seres vivos e a história da vida humana. Alguns estudantes apresentam dificuldades de aceitar a teoria evolutiva como um conhecimento científico válido, devido à falta de familiaridade suficiente ou à compreensão das evidências que sustentam a teoria (ALLMON, 2011).

Tanto o conhecimento de tópicos evolutivos como as opiniões sobre a origem do homem foram influenciados pelas variáveis: sexo, região do país em que o estudante reside, características socioeconômicas, religião e a proximidade com a ciência escolar e fora da escola. Mas observa-se que cada conjunto de relações aconteceu de maneira diversificada, evidenciando que algumas variáveis influenciaram as respostas dos estudantes, em menor ou maior intensidade. As variáveis atuam de maneira inter-relacionada, e as opiniões dos jovens são influenciadas principalmente pelo capital cultural e acesso a recursos educacionais, região do país em que o jovem reside, a relação com a religião e identificação com grupos religiosos, e a relação dos jovens com as aulas de ciências e a ciência fora da escola.

Dentre os dados brasileiros, os estudantes do Centro-Oeste, Norte e Nordeste destacaram com o menor conhecimento sobre temas evolutivos e maior influência de crenças pessoais nas suas respostas, particularmente, no que se refere à origem do homem. Observou-se que a religião desempenha um papel importante no cotidiano dos estudantes pesquisados, e em paralelo, são jovens com menor contato com temas científicos em espaços de educação não formal e informal. De modo geral, os estudantes procuram com pouca frequência pela ciência na internet ou centros científicos e possuem menor acesso a recursos educacionais (menor número de livros em casa; níveis baixos de escolarização dos pais). 
Quanto ao acesso a centros científicos, é importante ressaltar que espaços científicos como museus, zoológicos, jardins botânicos, entre outros, são escassos nessas regiões do país (OLIVEIRA, 2015).

Os dados de Oliveira (2015) revelam ainda que, embora a ciência apresente pouca influência nas respostas dos estudantes do Centro-Oeste, Nordeste e Norte sobre a origem dos seres vivos, os jovens parecem mais motivados com as aulas de ciências e apresentam posições mais positivas diante de afirmações sobre ciência e tecnologia e a carreira científica. Ainda, apesar de se verificar baixo conhecimento científico entre os estudantes dessas regiões, eles se demonstram mais positivos e motivados sobre os benefícios da ciência para sociedade.

Os estudos quantitativos desenvolvidos até o momento contribuíram ao constituir indicadores sobre a relação dos jovens com a teoria evolutiva. Entretanto, os dados sugerem a necessidade de mais pesquisas que possibilitem a compreensão da relação dos jovens com a teoria evolutiva e com a ciência presentes no cotidiano escolar dos jovens, bem como o entendimento dos contextos escolares e culturais.

O desenvolvimento de estudos com foco nas cidades que participaram do primeiro levantamento quantitativo nas regiões citadas certamente tem relevância social e científica, pois as respostas dos jovens dos grandes centros (Sudeste e Sul) comparadas com as de regiões com menores índices de desenvolvimento humano refletem diferenças socioeconômicas que se repetem em outras partes do mundo.

De acordo com Awan et al. (2011), as atitudes dos jovens sobre ciência variam consideravelmente em diferentes partes do mundo. Nos países em desenvolvimento, parecem mais interessados pela ciência e por temas relacionados com a ciência do que em países desenvolvidos. De modo geral, os dados dos jovens do Centro-Oeste, Norte e Nordeste refletem os resultados de países em desenvolvimento, nos quais se destacam posições positivas dos estudantes diante da ciência e tecnologia.

Da mesma forma, Sjøberg e Schreiner (2005) destacam que estudantes de países de baixo Índice de Desenvolvimento Humano (IDH) geralmente apresentam maior interesse pela ciência quando comparados com os jovens oriundos de países bem desenvolvidos. Os autores avaliam essas tendências como resultado de uma perspectiva geral de melhorias de condições de vida, pois a ciência passa a ser compreendida enquanto possibilidade de melhoria de condições materiais e de crescimento econômico.

Nesse sentido, dados mais focalizados e aprofundados sobre a relação dos jovens com a ciência, carreira científica e temas científicos estão sendo desenvolvidos, neste primeiro momento em escolas públicas de Cuiabá, com vistas a ampliar para as demais regiões citadas, o que deve contribuir com a compreensão das razões que parecem aproximar os jovens da ciência e ao mesmo tempo afastá-los de explicações científicas para fenômenos naturais.

Considerando os aspectos escolares, sociais e culturais que parecem influenciar a relação dos jovens (com idade média entre 14 e 16 anos) com a ciência e seus desdobramentos, o presente estudo tem como objetivo apresentar algumas percepções dos estudantes cuiabanos diante de temas científicos, escolhas profissionais e opiniões sobre temas evolutivos.

\section{Método}

Participaram desta pesquisa 406 estudantes (55,6\% meninos) matriculados no $1^{\circ}$ ano do Ensino Médio de escolas públicas de Cuiabá - MT, com idade entre 14 e 16 anos (participaram 
da pesquisa estudantes de 14 anos - 4,8\%; 15 anos - 61,2\%; 16 anos - 24,7\%; outros - 9,3\%). Esse público justifica-se, pois muitos estudos têm apontado que o interesse pela ciência e a tecnologia é completamente estruturada no espectro cognitivo durante a adolescência (PELLEGRINI, 2018).

Foi realizada uma amostragem do tipo probabilística através dos métodos: 1) amostragem estratificada; 2) amostragem por conglomerados.

O tamanho de amostra aproximado $(n)$ foi determinado utilizando a seguinte expressão:

$$
n=\frac{N p(1-p)}{(N-1) d^{*}+p(1-p)}
$$

na qual $d^{*}=d^{2} / Z_{\alpha / 2}^{2}, p(1-p)$ é a variância da população e $d$ é o limite máximo para o erro de estimação, estipulado pelo pesquisador.

Nesta pesquisa, foram considerados:

a) o tamanho da população, de 9821 ( $N=9821$ ) estudantes matriculados nas escolas públicas no ano de 2017;

b) uma proporção de 0,8 ( $p=0,8)$ de estudantes interessados pelas aulas de Ciências (OLIVEIRA, 2015);

c) coeficiente de confiança de $95 \%$, isto é, $Z_{\alpha / 2}=1,96$;

d) erro de amostragem de 4,00\% ( $d=0,040$ ), indicando que a distância entre a estimativa da amostra e o parâmetro populacional não deveria exceder esse valor.

Assim, utilizando a expressão (1), o tamanho da amostra obtido foi de 370 participantes. Considerando-se uma porcentagem de perdas de 30\%, o número final da amostra foi de 481 indivíduos. Nas coletas de dados, teve-se acesso a 406 estudantes matriculados em 15 escolas públicas, número que atende aos objetivos deste estudo e à representatividade do universo de jovens matriculados no $1^{\circ}$ ano do Ensino Médio.

O intuito das questões presentes no instrumento de coleta de dados era: verificar percepções, motivações, interesses e opiniões dos jovens sobre Ciência, tecnologia, questões ambientais e temas científicos. Os itens foram constituídos usando escalas do tipo Likert de 4 pontos, formato de múltipla escolha, e verdadeiro ou falso (OLIVEIRA, 2015). O presente trabalho ocupou-se principalmente das seções que verificaram as relações dos jovens com temas científicos, o interesse pelas aulas de Ciências e o conhecimento sobre temas evolutivos.

Para as coletas de dados, os pesquisadores visitaram as escolas, com autorização prévia do diretor ou coordenador de ensino, e aplicaram os questionários diretamente para os sujeitos da pesquisa. As aplicações duraram em média de 40 a 60 minutos, mediante os esclarecimentos acerca dos objetivos da pesquisa, orientações sobre o preenchimento do formulário e sobre os direitos de anonimato. Após as coletas, os questionários foram etiquetados e organizados em envelopes com identificação da escola e data. Em seguida, os formulários foram tabulados manualmente e iniciaram as análises descritivas.

Para as análises dos dados apresentados neste trabalho, foram feitas a descrição e as pontuações obtidas para cada variável, com auxílio do pacote estatístico Software Statistical 
Package for Social Science (SPSS) - Pacote Estatístico para as Ciências Sociais - versão 18.0. As distribuições de frequências foram organizadas e representadas pelas frequências absolutas, relativas e média/desvio-padrão. Também foram feitas análises que possibilitaram aprofundar a compreensão das relações entre as frequências identificadas e as diferenças entre grupos através dos testes de Qui-quadrado e o de Mann-Whitney.

\section{Resultados}

\section{Interesses científicos}

Entre os temas científicos de maior interesse dos respondentes, destacaram-se afirmações relacionadas ao cuidado com o ser humano. Na tabela 1 constam as respostas que atingiram a média mais próxima a 4 pontos, em uma escala de 1 a 4.

Tabela 1: Distribuição da amostra quanto aos interesses científicos de estudantes Cuiabanos ( $N=406)$

\begin{tabular}{lcccc}
\hline & Geral & Meninas & Meninos & \\
\cline { 1 - 3 } & \multicolumn{3}{c}{ Média (Desvio-padrão) } & p-valor \\
\hline $\begin{array}{lllll}\text { O câncer, o que sabemos e como podemos tratá- } \\
\text { lo }\end{array}$ & $3,06(1,03)$ & $3,28(0,96)$ & $2,88(1,06)$ & 0,000 \\
$\begin{array}{l}\text { As doenças sexualmente transmissíveis e como se } \\
\text { proteger delas }\end{array}$ & $3,10(1,04)$ & $3,20(1,01)$ & $3,03(1,06)$ & 0,087 \\
Como prestar primeiros socorros & $3,36(1,34)$ & $3,56(1,62)$ & $3,18(1,02)$ & 0,007 \\
\hline
\end{tabular}

Fonte: Elaboração própria.

Nas respostas dos estudantes, observaram-se diferenças significativas ao nível de 0,05, para a variável - sexo, nas seguintes afirmações: "O câncer, o que sabemos e como podemos tratá-lo", "Como prestar primeiros socorros". Nos resultados encontrados por Santos-Gouw (2013), que analisou os presentes itens para uma amostra de representatividade nacional, as meninas parecem mais interessadas por questões de saúde e bem-estar do humano. De maneira geral, o interesse por questões que envolvem o humano parece abranger tanto meninas como meninos cuiabanos. Neste sentido, a Biologia Humana representa um importante tema para engajamento dos estudantes no discurso científico, já que aparece com interesse intrínseco (SANTOS-GOUW, 2013).

De modo geral, a partir de uma análise mais detalhada dos itens dispostos no questionário, é possível verificar algumas tendências de resposta, semelhantes a resultados encontrados no Brasil e em outras regiões do mundo: entre os meninos há maior interesse por tecnologia, astronomia e agricultura, enquanto as meninas preferem saúde pessoal e pública (SANTOS-GOUW, 2013). Entretanto, as questões de saúde e significado da vida também parecem ser temas de interesse entre os meninos cuiabanos, como pode ser observado, por exemplo, a partir do item "A vida, a morte e a alma humana", cujas médias foram: meninas 3,07 $\pm 1,12$ e meninos 2,82 $\pm 1,22$ ( $p$-valor: 0,058).

Comparando aos dados analisados por Santos-Gouw, Mota e Bizzo (2016), a tendência observada entre os jovens brasileiros aparece mais acentuada entre os cuiabanos, pois observamos o interesse em aprender ciências na escola e atitudes positivas em relação à ciência escolar. 
Também foi verificado o interesse dos estudantes pelas aulas de Ciências (Tabela 2).

Tabela 2: Distribuição da amostra quanto à motivação pelas aulas de Ciências de estudantes cuiabanos $(\mathrm{N}=406)$

\begin{tabular}{|c|c|c|c|c|}
\hline & Geral & Meninas & Meninos & $\begin{array}{l}p- \\
\text { valor }\end{array}$ \\
\hline & \multicolumn{3}{|c|}{ Média (desvio-padrão) } & \\
\hline $\begin{array}{l}\text { Os conhecimentos que adquiro nas aulas de } \\
\text { Ciências serão úteis na minha vida cotidiana }\end{array}$ & $3,25(0,98)$ & $3,28(1,00)$ & $3,22(0,96)$ & 0,318 \\
\hline $\begin{array}{l}\text { Penso que a ciência que eu aprendo na escola } \\
\text { melhorará as minhas oportunidades de carreira }\end{array}$ & $2,91(1,15)$ & $2,99(1,13)$ & $2,85(1,16)$ & 0,246 \\
\hline $\begin{array}{l}\text { As aulas de Ciências estimulam a minha } \\
\text { curiosidade acerca das coisas que ainda não } \\
\text { conseguimos explicar }\end{array}$ & $3,08(1,11)$ & $3,17(1,06)$ & $3,01(1,16)$ & 0,240 \\
\hline $\begin{array}{l}\text { As aulas de Ciências aumentam o meu gosto } \\
\text { pela natureza }\end{array}$ & $2,92(1,14)$ & $2,89(1,20)$ & $2,95(1,10)$ & 0,729 \\
\hline Quero ser cientista & $1,68(1,06)$ & $1,59(1,02)$ & $1,75(1,09)$ & 0,095 \\
\hline $\begin{array}{l}\text { Gostaria de ter um emprego que lide com } \\
\text { tecnologia avançada }\end{array}$ & $2,84(1,20)$ & $2,64(1,22)$ & $3,01(1,17)$ & 0,003 \\
\hline
\end{tabular}

Fonte: Elaboração própria.

Os jovens consideram que os conhecimentos científicos são uteis para o cotidiano, que a ciência contribui para uma futura carreira e que aumenta a curiosidade e o interesse pela natureza. As respostas dos meninos parecem se destacar apenas no item "Gostaria de ter um emprego que lide com tecnologia avançada" $(3,01 \pm 1,17)$. Os resultados encontrados são semelhantes aos analisados por Santos-Gouw (2013), uma vez que se observa entre os jovens o interesse pelas aulas de Ciências.

No que se refere ao interesse por uma carreira científica, as médias atingidas são mais baixas, embora haja a valorização das ciências para o entendimento do cotidiano, bem como motivação para trabalhar com tecnologia, isso não reflete no interesse por seguir uma carreira científica $(1,68 \pm 1,06)$. Desinteresse pela área científica também foi verificado na questão "Você gostaria de fazer um curso técnico ou universitário na área científica?" (76,6\% assinalaram "não"), e não foi identificada diferença significativa para variável sexo (p-valor 0,560). Esses resultados se assemelham aos apresentados por Santos-Gouw, Mota e Bizzo (2016, p. 638), pois, "mesmo possuindo interesse acima da média pela ciência escolar, o jovem brasileiro demonstra pouco interesse pelos cientistas e suas vidas".

Tal desinteresse por uma carreira científica parece associado com a falta de entendimento sobre o trabalho do cientista. Pesquisas como as de Breunig, Amaral e Goldschmidt (2019) apontam que os jovens matriculados no Ensino Médio desconhecem cientistas importantes da história da Biologia, consequentemente desconhecem o trabalho científico e suas contribuições. As autoras destacam que ideias sobre o processo de construção da ciência e do trabalho científico podem ser prejudicadas pela maneira como a história da ciência é apresentada na Educação Básica.

De maneira geral, os cuiabanos parecem motivados pelas aulas de ciências e apresentam percepções positivas. Nesse sentido, também se verificou como os estudantes avaliam conhecimentos científicos que apresentam natureza controversa: os jovens motivados pela 
ciência escolar também estariam dispostos a responder a questões que envolvem as próprias origens a partir de explicações científicas?

\section{Teoria da evolução Biológica: opiniões e conhecimento}

Na seção anterior, destacaram-se resultados que sugerem jovens motivados pelas aulas de Ciências e interessados por temas da Biologia Humana. Entretanto, a proximidade da Ciência ganha uma nova dimensão quando os jovens são questionados sobre a teoria evolutiva. Diante de itens sobre a origem do homem, destacam-se os itens "Não saberia dizer" (34\%) e o homem se originou "da criação divina com as formas atuais" (24,5\%). As respostas dos estudantes apontam que a percepção sobre a origem humana é influenciada por questões culturais, já que 47,1\% optaram por afirmações que apresentam diferentes crenças presentes na sociedade (Tabela 3).

Tabela 3: Distribuição da amostra total quanto às opiniões sobre origem humana de estudantes cuiabanos $(\mathrm{N}=406)$

\begin{tabular}{lc}
\hline Uma evolução gradual devido a eventos aleatórios e seleção & $\%$ \\
natural & 19,0 \\
\hline Um plano divino que planejou e guiou a evolução & 15,8 \\
\hline Uma progressão natural guiada para atingir o homem & 6,8 \\
\hline Da criação divina, com as formas atuais & 24,5 \\
\hline Não saberia dizer & 34,0 \\
\hline Total & 100,0 \\
\hline
\end{tabular}

Fonte: Elaboração própria

A maioria optou por respostas que envolvem crenças pessoais para a origem humana, mas em seguida destacam-se as respostas dos estudantes que não sabem dizer sobre a própria origem. Neste caso, deve-se analisar se as opções assinaladas provêm de posicionamentos religiosos ou se realmente os jovens desconhecem o tema.

Considerou-se avaliar a percepção dos estudantes sobre o próprio conhecimento, por meio da autodeclaração. Assim, entendendo que o conhecimento é resultado das relações e interações do indivíduo com o universo pelo qual serão aceitos conceitos a ponto de apreendê-los como verdadeiros ou válidos (COBERN, 1994), nesta pesquisa, os estudantes pontuaram seu posicionamento diante de tópicos da teoria evolutiva, a partir da autodeclaração do próprio conhecimento, possibilitando inferências sobre os temas que são avaliados como válidos pelos estudantes.

Na tabela 4, observa-se que há temas evolutivos conhecidos com maior frequência, e os percentuais nos itens "falso" e "não saberia dizer" são mais baixos: "Os fósseis são evidências de seres vivos que viveram no passado" - 69,6\% consideram verdadeiro; "As espécies atuais de animais e plantas se originaram de outras espécies do passado" - 60,4\% consideram verdadeiro; "A evolução biológica ocorre tanto em plantas como em animais" - 60,1\% consideram verdadeiro; "As características dos seres vivos mudaram ao longo do tempo, favorecendo a diversidade biológica" - 55,2\% consideram verdadeiro). 
Tabela 4: Distribuição da amostra total quanto ao conhecimento de tópicos da teoria evolutiva $(\mathrm{N}=406)$

\begin{tabular}{lll}
\hline & & $\%$ \\
\hline A formação do planeta Terra se deu há cerca de 4,5 bilhões de anos & $\mathrm{V}^{1}$ & 43,1 \\
& $\mathrm{~F}^{2}$ & 12,1 \\
& $\mathrm{~N} / \mathrm{S}^{3}$ & 44,8 \\
\hline Os fósseis são evidências de seres vivos que viveram no passado & $\mathrm{V}$ & 69,6 \\
& $\mathrm{~F}$ & 12,5 \\
& $\mathrm{~N} / \mathrm{S}$ & 17,9 \\
\hline As espécies atuais de animais e plantas se originaram de outras & $\mathrm{V}$ & 60,4 \\
espécies do passado & $\mathrm{F}$ & 15,1 \\
& $\mathrm{~N} / \mathrm{S}$ & 24,5 \\
\hline A evolução biológica ocorre tanto em plantas como em animais & $\mathrm{V}$ & 60,1 \\
& $\mathrm{~F}$ & 16,7 \\
\hline A espécie humana descende de outra espécie de primata & $\mathrm{N} / \mathrm{S}$ & 23,3 \\
\hline As características dos seres vivos mudaram ao longo do tempo, & $\mathrm{V}$ & 35,3 \\
favorecendo a diversidade biológica & $\mathrm{F}$ & 28,5 \\
\hline & $\mathrm{N} / \mathrm{S}$ & 36,2 \\
\hline Organismos diferentes podem ter um ancestral comum & $\mathrm{V}$ & 31,7 \\
& $\mathrm{~F}$ & 20,8 \\
& $\mathrm{~N} / \mathrm{S}$ & 47,5 \\
\hline & $\mathrm{F}$ & 24,1 \\
& $\mathrm{~F} / \mathrm{S}$ & 20,8 \\
\hline
\end{tabular}

Legenda: V - Verdadeiro; F - Falso; N/S - Não saberia dizer. Fonte: Elaboração própria

Por meio da tabela 4, também se identifica que alguns temas parecem mais confusos para os estudantes havendo maior distribuição nas opções: falso e não saberia dizer. Por exemplo, as afirmações que tratam sobre a origem do ser humano e da ancestralidade comum entre as espécies alcançaram percentuais mais altos na opção "Não saberia dizer". Quanto à idade da Terra, os estudantes pareceram indecisos, havendo empate entre os que consideram verdadeiro e aqueles que desconhecem a informação.

Além disso, os jovens demonstraram que não possuem convicção sobre a origem do homem e a ancestralidade comum entre os organismos, particularmente, a ancestralidade do homem. Concluíram o Ensino Fundamental desconhecendo alguns preceitos sobre a idade e história da vida na Terra, principalmente no que se refere ao humano, e o mais preocupante é a falta de clareza sobre o parentesco entre as espécies, uma vez que não reconhecem o conceito de ancestralidade em comum.

Donnell, Kazempour e Amirshokoohi (2009) também identificaram que os estudantes norte-americanos do Ensino Médio possuem diferentes níveis de aceitação diante de temas evolutivos. Afirmam que a maioria dos jovens aceita aspectos sobre a teoria, no que se refere 
à microevolução e à macroevolução; mas aceitam com menor frequência a evolução humana, por um lado motivados por aspectos emocionais e crenças pessoais, e, por outro, pela falta de dedicação do currículo escolar de ciências ao tema.

Quanto à ancestralidade comum, que também aparece como um assunto desconhecido entre os jovens, Alters e Alters (2001) ressaltam que juntamente com a seleção natural são temas que tornam a evolução uma teoria norteadora da biologia. A falta de conhecimento sobre esses tópicos possivelmente dificulta a compreensão da dinâmica das populações e de conceitos mais complexos, como os ecossistemas e os diferentes níveis que compreendem a relação entre os organismos vivos e o meio ambiente.

A partir dos resultados encontrados, é possível dizer que os estudantes não possuem conhecimento suficiente sobre a evolução biológica, a fim de permitir-Ihes tomar uma posição inequívoca em relação a esse assunto. Prinou e Skordoulis (2008) encontraram dados semelhantes e discutem que a falta de conhecimento de conceitos simples da teoria evolutiva parece consequência de um currículo escolar que trata o tema de maneira marginalizada. Enquanto o ensino de biologia não for compreendido e ensinado a partir da evolução biológica como eixo norteador, os estudantes concluirão o ensino básico desconhecendo a dinâmica do mundo natural.

Prinou e Skordoulis (2008) pesquisaram as opiniões de estudantes gregos matriculados no último ano do Ensino Fundamental sobre tópicos da teoria da evolução biológica. A amostra foi composta por 411 estudantes (52,9\% meninas) de 12 escolas. Os resultados apontaram que eles aceitam o conceito da evolução biológica, pois $77,6 \%$ concordaram que "Espécies atuais são resultado de processos evolutivos que vêm ocorrendo há milhões de anos"; entretanto, 11,7\% discordaram e 10,7\% apontaram que "Não sabem". Além disso, a maior parte dos estudantes discordou das afirmações: "Todos os organismos aparecerem ao mesmo tempo" (89,3\% discordaram; 5,4\% concordaram; 5,3\% não souberam responder); "Milhões de anos atrás havia as mesmas espécies de plantas e animais como os que vivem hoje" (86,2\% discordaram; 8,8 concordaram; 5,1\% não souberam responder).

Quanto à origem do homem, 58,6\% concordaram que o "Homem evoluiu a partir de formas inferiores da vida"; 21,9\% discordaram e 19,5\% não souberam responder. Sobre a origem comum dos organismos, 53,3\% dos jovens aceitaram que "Todas as espécies de organismos são descendentes de um ancestral comum de um passado distante", 30,4\% discordaram e 18,7\% não souberam.

A respeito da coexistência de humanos e dinossauros, 46,7\% discordaram de que "As pessoas e dinossauros coexistiram no mesmo período", 34,5\% concordaram e 18,7\% não souberam responder. Em relação à origem da vida na Terra, 69,6\% concordaram que a "Evolução explica como a vida começou na Terra", 13,2\% discordaram e 17,3\% não souberam responder.

Nas questões abertas, os autores perceberam que os estudantes associam a palavra evolução a desenvolvimento, progresso, uma mudança nos indivíduos em si e não a alterações em nível de populações. Além disso, não utilizam a seleção natural para explicar as mudanças nos organismos e, embora demonstrem uma visão positiva em relação a alguns tópicos da teoria evolutiva, desconhecem aspectos centrais da teoria.

Os resultados encontrados por Prinou e Skordoulis (2008) são semelhantes aos desta pesquisa, pois, enquanto alguns itens são considerados válidos entre os estudantes, como a percepção de que os seres vivos mudam ao longo do tempo e que a evolução biológica acontece na natureza, temas relacionados à ancestralidade comum e à origem humana 
parecem confundir os jovens, de modo que aumenta a frequência de estudantes que consideram as afirmações falsas ou não sabem responder.

Diante desses dados, concorda-se com Prinou e Skordoulis (2008), que consideram esses resultados como consequência de um currículo escolar cuja teoria da evolução biológica é colocada em segundo plano e apresentada descontextualizada dos fenômenos biológicos. 0 ensino de biologia não contribui na formulação de redes conceituais que permitam aos estudantes compreender o mundo vivo a partir da mudança biológica. Desta forma, os estudantes criam suas próprias formulações, agregando e sintetizando alguns conceitos científicos com crenças pessoais, ou atribuem ao sistema vivo conceitos de "progresso" e "necessidade".

Os resultados encontrados sugerem que os estudantes cuiabanos não apresentam uma rejeição direta com os temas evolutivos, consideram válidas as explicações científicas na compreensão da natureza, pois reconhecem a validade do conceito da evolução biológica, os fósseis como evidências dos seres vivos que viveram no passado, que as espécies mudam ao longo do tempo. Entretanto, a ancestralidade comum e a origem humana não são reconhecidas como verdadeiras. Os resultados encontrados por Oliveira e Bizzo (2015) para as regiões Centro-Oeste, Norte e Nordeste parecem mais acentuadas entre os estudantes cuiabanos.

Desta forma, a análise dos posicionamentos culturais dos estudantes acerca da origem humana indica que a falta de conhecimento sobre o tema pode influenciar as respostas dos estudantes, pois se a escola não apresenta uma opção científica para explicar a dinâmica da natureza e dos seres vivos, os jovens buscam responder a partir das estruturas cognitivas disponíveis, neste caso a partir de crenças pessoais.

Os estudantes não parecem bem informados sobre o tema, a ponto de optarem conscientemente entre uma perspectiva religiosa ou científica. Neste sentido, interessa entender, ao longo do desenvolvimento deste projeto de pesquisa, as razões que motivam os estudantes que optaram pela opção "Falso". Questiona-se: pontuar determinada informação como falsa é resultado da falta de subsídios científicos que permitem reconhecer a validade do conceito ou se trata de um posicionamento cultural permeado por motivações emocionais?

Neste ponto, pauta-se o desafio de compreender qualitativamente cada contexto e situações em sala de aula que influenciam essas relações, para garantir maior aproximação dos estudantes à ciência e a temas científicos (trabalho que será desenvolvido na segunda etapa deste projeto de pesquisa). A pluralidade cultural brasileira sugere que as relações entre conhecimentos científicos e crenças pessoais acontecem de maneira diversa, no entanto, é importante destacar que a dificuldade de um posicionamento mais inequívoco diante de termos evolutivos resulta, possivelmente, de um ensino da teoria da evolutiva descontextualizado de fenômenos biológicos. A teoria da evolução não parece ser um conceito que os jovens dominam, assim, permite que expliçções alternativas sejam acomodadas com maior frequência.

Essa tendência pode ser observada pela presença de opiniões que sintetizam a ciência e a cultura, representadas pelo item que associa a origem humana ao planejamento divino, que pode suscitar que alguns estudantes busquem por explicações que conciliam o conhecimento científico a suas crenças pessoais. Por um lado, parece que a cultura influencia os jovens a aproximar ciência e religião como empreendimentos complementares e, por outro, parece 
haver falta de subsídios conceituais que contribuam para que os jovens interpretem o mundo vivo a partir de explicações científicas.

Diante dos resultados, destaca-se a oscilação de respostas entre os jovens, quando se trata da origem e evolução humana. A visão de mundo depende fundamentalmente da organização do conjunto de pressupostos ou suposições, que predispõem o sentir, pensar e agir. A visão de mundo de um indivíduo é formada no contexto sociocultural em que ele se desenvolveu e no qual se insere. Muitas vezes, a religião é interpretada como uma visão de mundo ou filosofia, por exemplo, a visão cristã do mundo. De fato, a religião tem uma força educacional especialmente poderosa na mente de uma criança em crescimento, influenciando fortemente os contornos da sua visão de mundo. No entanto, muitos outros fatores influenciam as ideias de uma criança em crescimento, logo, a religião é apenas uma parcela do conteúdo específico de uma visão de mundo (COBERN, 1991).

\section{Implicações para o Ensino de Ciências}

Ouvir o estudante é uma maneira de transformar a escolaridade, uma vez que torna o currículo mais relevante para as necessidades e os interesses dos alunos. Conhecer os temas que interessam os alunos e considerá-los nas práticas educativas pode melhorar sua motivação e contribuir no processo de ensino-aprendizagem (JENKINS, 2006 apud SANTOSGOUW, 2013, p. 197). No presente estudo, a Biologia Humana se destaca entre os temas científicos de maior interesse entre os jovens, o que parece uma importante via para aproximar os estudantes de temas científicos, tornando a aprendizagem mais significativa.

O engajamento dos estudantes no discurso científico poderá ser impulsionado por temas que apresentam interesse intrínseco, mas ressalta-se que o papel da escola é motivar e incentivar novos interesses, ampliando o repertório científico dos jovens estudantes.

Neste estudo, observa-se que o interesse por questões da Biologia Humana não parece associada com uma visão científica da origem do homem. A partir dos resultados encontrados, foi possível verificar algumas lacunas nas percepções dos estudantes diante da teoria da evolução biológica. Enquanto para os cuiabanos parecem mais evidentes as mudanças dos seres vivos ao longo tempo, há pouco conhecimento sobre os processos que levaram a esta mudança. O ser humano ainda aparece para alguns estudantes como resultado de uma criação especial e, para outros, como um tema desconhecido, o que sugere que a ideia de mudança gradual não é facilmente associada ao homem.

Quando a escola não apresenta subsídios teóricos que contribuem para responder a questões da existência humana, as perspectivas culturais ganham força e alcance na visão de mundo dos estudantes. $O$ aluno reconhece a ação de um ser sobrenatural que conduziu a origem da vida, porque, em sua classificação, existem categorias teológicas na representação do mundo. Também se supõe que as categorias biológicas são relativamente mais fracas na visão de mundo deste estudante.

Os educadores estão sendo confrontados mais do que nunca a fornecer uma educação científica significativa para todos os alunos (COBERN; ELLINGTON; SCHORES, 1990), de maneira que os diferentes grupos sociais tenham acesso e se sintam bem-sucedidos na educação científica. Os resultados encontrados na presente pesquisa apontam que aspectos culturais influenciam as opiniões dos jovens acerca da teoria evolutiva e que, possivelmente, alguns estudantes precisam de maior apoio para engajamento na cultura científica. 


\section{Agradecimentos}

Ao Laboratório de Estatística, projeto de extensão do Departamento de Estatística da Universidade Federal do Mato Grosso (UFMT), pelas consultorias estatísticas.

\section{Referências}

ALTERS, B. J.; ALTERS, S. M. Defending evolution in the classroom: a guide to the creation/evolution controversy. Canada: Jones and Bartlett Publishers, 2001. 261p.

BIZZO, N. M. V. From Down House landlord to Brazilian high school-students - what has happened to evolutionary knowledge on the way? Journal of Research in Science Teaching, v. 31, p. 537-556, 1994.

BIZZO, N. M. V.; ALMEIDA, A. V.; FALCÃO, J. T. R. A compreensão de estudantes dos modelos de evolução biológica: duas aproximações. 2007. Disponível em: http://axpfep1.if.usp.br/ profis/arquivos/vienpec/CR2/p1148.pdf. Acesso em: 16 maio 2014.

BIZZO, N. M. V.; EL-HANI, C. N. O arranjo curricular do ensino de evolução e as relações entre os trabalhos de Charles Darwin e Gregor Mendel. Filosofia e História da Biologia, v. 4, n. 1, p. 235-257, 2009b.

BREUNIG, E. T.; AMARAL, A. S.; GOLDSCHMIDT, A. I. História da ciência: revelando concepções fragmentadas a partir de imagens de cientistas. Amazônia: Revista de Educação em Ciências e Matemáticas, v. 15, n. 33, p. 134-150, 2019.

COBERN, W. W. Point: Belief, Understanding, and the Teaching of Evolution: Journal of Research in Science Teaching, v. 31, n. 5, 1994, p. 583-590.

COBERN, W. W. World view theory and science education research, NARST Monograph. Manhattan, KS: National Association for Research in Science Teaching, 1991. Disponlvel em: http://scholarworks.wmich.edu/cgi/viewcontent.cgi?article=1043\&context=science_slcsp.

Acesso em: 10 out. 2014.

COBERN, W. W.; ELLINGTON, J. E.; SCHORES, D. M. A Logico-Structural, Worldview Analysis of the Interrelationship between Science Interest, Gender, and Concept of Nature. Scientific Literacy and Cultural Studies Project, v. 4, n. 1, p. 1-18, 1990.

DONNELLY, L. A.; KAZEMPOUR, M.; AMIRSHOKOOHI, A. High school students' perceptions of evolution instruction: acceptance and evolution learning experiences. Research in Science Education, v. 39, n. 5, p. 643-660, 2009.

MOTA, H. S. Evolução Biológica e Religião: atitudes de jovens estudantes brasileiros. 2013. 275p. Tese (Doutorado em Educação) - Faculdade de Educação, Universidade de São Paulo, São Paulo, 2013.

NERESINI, F.; CROVATO, S.; SARACINO, B. Scienza e nuove generazioni - I risultati dell'indagine internazionale ROSE. Vicenza: Edizioni Observa Science in Society, 2010.

OSBORNE, J. A.; SIMON, S. B.; COLLINS, S. Attitudes towards science: A review of the literature and its implications. International Journal of Science Education, v. 25, n. 9, p. 1.049-1.079, 2003. 
OLIVEIRA, G. S. Estudantes e a evolução biológica: conhecimento e aceitação no Brasil e Itália. 2015. 315f. Tese (Doutorado) - Faculdade de Educação, Universidade de São Paulo, São Paulo, 2015.

OLIVEIRA, G. S.; BIZZO, N. Evolução biológica e os estudantes brasileiros: conhecimento e aceitação. Investigações em Ensino de Ciências, v. 20, n. 2, p. 161-185, 2015.

PELLEGRINI, G. Adolescents between science, technology and future: the results of the 2017 Observa-PRISTEM Bocconi survey. Lettera Matematica, n. 6, p. 03-08, 2018.

PRINOU, L.; HALKIA, L.; SKORDOULIS, C. What conceptions do Greek school students form about biological evolution? Evolution: Education and Outreach, v. 1, n. 3, p. 312-317, 2008.

QUINN, F.; LYONS, T. High School Students' Perceptions of School Science and Science Careers: A Critical Look at a Critical Issue. Science Education International, v. 22, n. 4, p. 225 238, 2011.

SANTOS-GOUW, A. M. As opiniões, interesses e atitudes dos jovens brasileiros frente à ciência: uma avaliação em âmbito nacional. 2013. 242p. Tese (Doutorado em Educação) Faculdade de Educação, Universidade de São Paulo, São Paulo, 2013.

SANTOS-GOUW, A. M.; MOTA, H. S.; BIZZO, N. O jovem brasileiro e a Ciência: possíveis relações de interesse. Revista Brasileira de Pesquisa em Educação em Ciências, v. 16. n. 3, p. 627-648, 2016.

VAN GRIETHUIJSEN, R. A. et al. Global Patterns in Students' Views of Science and Interest in Science. Research in Science Education, p. 1-23, 2014. 